\title{
Study of College English Teacher Participation in Curricular Reform
}

\author{
Yuanqi Song ${ }^{1, *}$ \\ ${ }^{1}$ Southwest University, Chongqing, China \\ * Correspondence: Southwest University, Chongqing, China. E-mail: song200702@163.com
}

Received: March 6, 2016 Accepted: March 15, 2016 Online Published: March 21, 2016

doi:10.5430/wjel.v6n1p35 URL: http://dx.doi.org/10.5430/wjel.v6n1p35

\begin{abstract}
Teachers play a decisive role in any curricular reform. College English reform has been implemented for many years. How do the majority of the teachers participate in the reform? Based upon the self-compiled scale of university teacher participation in curricular reform, this study tries to describe a panorama of teacher participation. By employing the methods of comparing the values of mean, mode, SD and frequencies of particular value, the author finds that college English teachers did not participate into the reform actively. By using the analysis of independent sample $\mathrm{T}$ test and ANOVAs, the author finds that there are many significant differences among factors as gender, age, types of universities and districts.
\end{abstract}

Keywords: curricular reform; teacher participation; significant difference

\section{Research Background}

Research shows that reform can not succeed without teacher participation (Bee, 2008). The success of education reform depends a lot on teachers since the implementation of reform plans is carried out completely by teachers. Therefore, to study teacher participation and the effect of it plays a significant role in today's reforms.

Curricular reform refers to the changes and modifications of the curricular as one defines, and it can be of big or small scales. Curricular reform and its implementation are constrained by many factors (Richards, 2003:94), but "teachers are in the center of any innovation which expects of improvement of teaching and learning (Ying, 2006)". Without teachers' active participation, there would not have the success of curricular reform, thus, to lead the implementers into the reform is very essential (Markee, 1997:172). However, to know the state of participation of the teachers concerned should be the first important step to promote teacher participation.

University curricular reforms in China are frequent, and one of the big problems is the lack of teacher participation (Jiang, 2005). Reform of College English Curricular, which provides learning experiences for the non-English majors, is one important aspect of university curricular reforms in China. All universities are required to implement the reform by China's Bureau of Education in 2007. And research shows that till 2010, about $90 \%$ of Chinese Universities have adopted the reform (Wang \& Wang, 2011), which shows the influence of College English reform. It is carried out by the Education Bureau of China and has uniformed reform guidelines, measures and several main course books. College English and its reform exert great influence to millions of college students. As a result, studying college English teacher participation in the reform is of great significance.

Teacher participation has been defined as teachers' joining into an organization, carrying out its activities, and providing advices to the activities (Dong, 2008) or one kind of cooperation as well as the right to decide their own teaching materials (Wang, 2000) or teacher participation into the process of decision-making, development, implement and assessment activities (Zhou, 2002). Others think that teacher participation is the mechanism of selectively allot powers to teachers (Merschen, 2014: 44).

In this study, teacher participation is defined as teachers actively participate into a series of curricular reform affairs, including the process of decision-making, reform designing, material developing, implementing and assessment of curricular reforms.

Studying the definition and significance of teacher participation doesn't guarantee a complete understanding of teachers' experiences in curricular reform. Up to today, there don't have many quantitative researches about college 
English teacher participation in the reform. Therefore, this study focuses on how deeply the college English teachers participated in the reform and try to find out the differences between groups of teachers. This is to provide a panorama of teacher participation, so as to promote the implementation of College English Reform in the future.

\section{Study Design}

\subsection{Scale Composition}

Since there hasn't a proper scale to measure the degree of college English teacher participation in the reform, the author composed a scale through methods of literature review, interviewing, category analysis and so on. The scale, which is composed of 5 sub-scales with 44 items, is named as University Teacher participation in Curricular Reform (UTP thereof). The five sub-scales are called Sense of Participation (SP), Attitudes towards Participation (AtP), Environment of Participation (EnP), Actions of Participation (AcP) and Effects of Participation (EfP). The scale adopts Likert style, each item is a statement followed by 5 degrees of agreement, which stand for from "Completely disagree" to "Completely agree". The choices are valued as 1 to 5 respectively, and the higher is the score, the better is the result.

\subsection{Sampling and Test}

Since the number of the targeted people of the study is large, this study employed two sampling methods: "convenience sampling" of "non-probability sampling" and "cluster sampling" of "probability sampling" (Qin, 2009:142). The former was employed among teachers who took part in the professional development seminars sponsored by some famous publishers as Shanghai Foreign Language Press, Foreign Language Teaching and Research Press, Higher Education Press in July and August of 2014. These teachers gathered from all part of China, and they were chosen by their universities by random. About 700 questionnaires were delivered in this way, and 506 questionnaires were gotten back.

The latter method was employed in the second semester in 2014. 11 universities were chosen from the East, Central and West Districts, covering 5 key universities and 6 general universities, and they all adopted the reform. 30-50 questionnaires were sent to each university according to the teachers available there through mailing from September to October. About 460 questionnaires were delivered in this way, and 407 questionnaires were gotten back.

Altogether, about 1160 questionnaires were delivered, and 913 questionnaires, about 78.7\%, were gotten back. All the data were recorded into files, checked, and employed the normal method of mean to replace the missing value (Qin, 2009:191). If there were about $15 \%$ of the items missing, the questionnaire would be regarded as invalid. Through this way, there are altogether 844 valid questionnaires, about $72.8 \%$ of the total questionnaire delivered.

\subsection{Reliability and Validity Test}

Reliability refers to the extent to which scores of the scale are free from errors of measurement. It is tested by using the method of internal consistency (Alpha) analysis. Validity refers to the extent to which a scale can measure what it has meant to measure. It is tested by using the method of exploratory factor analysis and confirmatory factor analysis.

By employing SPSS21.0, the reliability and validity of the scale are tested. Analysis shows that it is a rather good scale (shown in Table 1). Most of the 44 items' factor load values are above 0.6, and the accumulation of contributions ratio of each category is $50.396 \%$, which has reached the acceptable criteria of social science measurement ( $\mathrm{Wu}, 2014: 233)$. These support that the theoretical factor structure is rational.

The Standard Cronbach's Alpha value of the scale is 0.917, except the factor of AtP, whose Alpha value is 0.744, all the others are above 0.8 , even above 0.9 , which shows it has a very good internal consistency.

Table 1. Factor Analysis of the Internal Structural Categories of UTP

(The principal component method, orthogonal rotation, $\mathrm{N}=844$ )

\begin{tabular}{llllll}
\hline Factors & EnP & EfP & SP & AcP & AtP \\
\hline Eigen Value & 5.274 & 4.960 & 4.487 & 4.381 & 3.061 \\
Contribution Ratio \% & 11.987 & 11.272 & 10.197 & 9.956 & 6.958 \\
Accumulation of CR \% & 11.987 & 23.259 & 33.456 & 43.412 & 50.369 \\
Standard Cronbach's Alpha & .881 & .903 & .852 & .849 & .745 \\
\hline
\end{tabular}


AMOS 21.0 is applied to the Confirmatory Factor Analysis of the internal structural components. Fitting degree refers to the degree of conformity of the structural part and the actual measurements. Parts of the residuals of the same factor are correlated according to the data in Model Fit Indices. The fitting degree of this study is shown in Table 2.

Table 2. Fitting Degree of the Confirmatory Factor Analysis of UTP

\begin{tabular}{llllllll}
\hline Model & $\chi^{2}$ & $R M R$ & $R A S E A$ & $N F I$ & $I F I$ & $C F I$ & $\chi^{2} / \mathrm{df}$ \\
\hline UTP Model & 1965.091 & 0.0649 & 0.040 & 0.893 & 0.936 & 0.936 & 2.334 \\
\hline
\end{tabular}

It is generally believed that if the value of $\chi^{2} / \mathrm{df}$ is small, the fitting degree of the model is good. The fitting degree in this study is acceptably good. If the value of the fitting degree index of NFI, CFI, IFI is approaching 1, and RASEA is smaller than 0.08 , RMR is smaller than 0.06 , the theoretic assumption of the study is better. The values of NFI, CFI and IFI are all above 0.90, and RASEA $(=0.040)$ is lower than 0.08 , RMR $(=0.0649)$ is lower than 0.06 in this study. These demonstrate that the fitting degree of the five factors is good, having a good structural validity.

Judging from the above, we can draw the conclusion that UTP is composed of 44 items with the five factors. By way of filtering degree analysis, the indexes of each are feasible, and this further proves that there is good consistency between the theoretical model and the empirical research. It demonstrates the good structural validity of the model.

Both the reliability and validity tests demonstrate that UTP is a rather good measuring scale to study the participation of teachers in university curricular reform.

\section{Analysis of College English Teacher participation in the Reform}

\subsection{General State of Teacher Participation}

Through the analysis of the values of mean, mode, SD of the scale and its five factors and frequencies of particular items, we can draw a picture of college English teacher participation in the reform.

Table 3. Values of Mean, Mode, SD of Teacher Participation ( $\mathrm{N}=844)$

\begin{tabular}{lllllll}
\hline & SP & AtP & EnP & AcP & EfP & Scale \\
\hline mean & 4.3299 & 3.4704 & 3.0271 & 3.7965 & 3.5172 & 3.6282 \\
mode & 5.00 & 3.57 & $3.00^{\mathrm{a}}$ & 4.00 & 4.00 & $2.83^{\mathrm{a}}$ \\
SD & .353 & .534 & .545 & .383 & .432 & .196 \\
Mean (below 3.0) \% & 2.6 & 22.6 & 42.8 & 7.0 & 15.3 & 7.5 \\
Mean (3.0-4.0) \% & 16.1 & 50.9 & 48.1 & 52.7 & 60.1 & 73.3 \\
Mean (above 4.0) \% & 81.3 & 26.5 & 9.1 & 42.3 & 24.6 & 19.2 \\
\multicolumn{7}{l}{ a. More modes, and only the smallest one shown here. }
\end{tabular}

The analysis shows that college English teachers have a good sense of participation. The values of mean, mode, SD of SP are 4.3299, 5 and 0.353 , ratio of the average mean above 4.0 (Note 2) is over $80 \%$, which show that teachers all realize that participation in the reform is their right and responsibility.

Contrast to this realization is the negative attitudes towards participation. The values of mean, mode, SD of AcP are $3.4704,3.57$ and 0.534 , ratio of the average mean above 4.0 is only $26.5 \%$, more than $50 \%$ of the average mean is between 3.0 and 4.0 , up to $22.6 \%$ is under 3.0 , which show that teachers have different attitudes towards participation, someone is active and someone is quite negative. Checking the frequencies of particular items also proves this result. For example, up to $64.5 \%$ of the teachers think that reform is a waste of time, and about $30 \%$ of them said they have to participate in the reform. $52.6 \%$ of the teachers hint that they do not want to implement the reform curricular, and $61.5 \%$ of them don't want to take the risk of implementing the reform.

Teachers' negative attitudes towards participation are partly explained from the analysis of environment of participation (EnP). Analysis shows that the environment for teacher participation is rather frustrating. The values of 
mean, mode and SD are 3.0271, 3 and 0.545 , ratio of the average mean above 4.0 is merely $9.1 \%, 48.1 \%$ of it is between 3.0 and 4.0, 42.8\% is lower than 3.0, which show that most teachers regard the EnP as poor. Checking the frequencies of particular items also proves this result. For example, only about $1 / 3$ of the teachers think that the culture of the university is favorable for their participation. About $71 \%$ of the teachers think that they do not possess the channels to negotiate the curricular reform. Only $27 \%$ of the teachers said that they can get extra help from their university.

Based on the negative attitudes and poor condition for participation, teacher participation activities can be inferred. Actions of participation need enhancing. The values of mean, mode and SD are 3.7965, 4 and 0.383 , ratio of the average mean above 4.0 is about $42.3 \%, 52.7 \%$ of it is between 3.0 and 4.0 , about $7 \%$ is under 3.0 , which show more than half of the teachers are not sure whether they have taken actions to implement reform. Frequency analysis of particular items shows that only $42.6 \%$ of the teachers have tried to understand their reform plans, about $67 \%$ of them think that they always interpret the reform according to their own believes, knowledge, attitudes, etc. And about $55 \%$ of them reported that colleagues were often talking about the issues of the reform concerning with themselves. There are $71.8 \%$ of the teachers reported that they seldom discussed with colleagues how to improve their teaching.

The effects of the participation includes teachers' change, students' change and the change of university culture, which are not ideal, though most of the teachers reported that they had changed a lot in views about education, curricular and teaching methods. The values of mean, mode and SD are 3.5172, 4 and 0.432 , ratio of the average mean above 4.0 is only $24.6 \%, 60.1 \%$ of it is between 3.0 and $4.0,15.3 \%$ is lower than 3.0 , which show only a small portion of teachers think there is a favorable change after the reform. Frequency analysis of particular items shows that about $60 \%$ of the teachers think that their students changed little in their learning methods, abilities and results. This indicates that the reform has not reached the goal of achieving the "development of individualized study methods and the autonomous learning ability on the part of students" (Department of Higher Education, 2007: 23).

In general, the degree of teacher participation in college English reform is not very high. The values of mean, mode and SD of the scale are 3.6282, 2.83 and 0.196 , ratio of the average mean above 4.0 is merely $19.2 \%, 73.3 \%$ of it is between 3.0 and 4.0, which show that most teachers did not actively participate into the reform.

\subsection{Group Differences of Teacher Participation}

\subsubsection{Differences in Gender, Age, Degrees and Professional Identities}

Teachers' degrees include three levels: bachelor, master and doctor, and their professional identities include four levels: professor, associate professor, lecturer and assistant professor. Analysis shows that there are not any significant differences between these categories, and this means these categories do not impact college teacher participation from the angle of the scale. Analysis of teachers' gender and age shows that there are significant differences in some aspects of the scale (shown in table 4 and 5).

Table 4. Independent Sample T Test of Gender

\begin{tabular}{lllllll}
\hline & Gender & $\mathrm{N}$ & $\mathrm{mean}$ & $\mathrm{SD}$ & $\mathrm{t}$ & Sig.(two-tailed) \\
\hline $\mathrm{SP}$ & 1 & 161 & 4.2830 & .64859 & -1.115 & .265 \\
& 2 & 683 & 4.3410 & .58050 & & \\
AtP & 1 & 161 & 3.3904 & .72839 & -1.545 & .123 \\
& 2 & 683 & 3.4892 & .73025 & & \\
\multirow{2}{*}{ AcP } & 1 & 161 & 3.6988 & .70648 & -2.234 & .026 \\
& 2 & 683 & 3.8195 & .59415 & & \\
EnP & 1 & 161 & 3.0118 & .75261 & -.293 & .770 \\
& 2 & 683 & 3.0307 & .73502 & & \\
EfP & 1 & 161 & 3.4298 & .77030 & -1.654 & .100 \\
& 2 & 683 & 3.5378 & .62605 & & \\
\multirow{2}{*}{ Scale } & 1 & 161 & 3.5627 & .48451 & -1.945 & .053 \\
& 2 & 683 & 3.6437 & .43144 & & \\
\hline
\end{tabular}

Among college English teachers, there are far less male teachers (group 1) than female teachers (group 2). The analysis of independent sample $T$ test shows that there is little difference among male group and female group except the sub-scale of AcP. Female group has a higher score than male group in AcP, and the difference is significant $\left(\mathrm{M}_{\mathrm{m}} \pm \mathrm{SD}=3.6988-2.234, \mathrm{M}_{\mathrm{f}} \pm \mathrm{SD}=3.8195-2.234, \mathrm{t}=-2.234, \mathrm{df}=842.389, \mathrm{p}=0.026<0.05\right)$, which show that female 
teachers take more active actions in participating in the reform.

Table 5. Independent Sample T Test of Age

\begin{tabular}{lllllll}
\hline & Age & $\mathrm{N}$ & mean & SD & t & Sig.(two-tailed) \\
\hline \multirow{2}{*}{ SP } & 1.00 & 382 & 4.3869 & .54342 & 2.540 & .011 \\
& 2.00 & 462 & 4.2828 & .62970 & & \\
AtP & 1.00 & 382 & 3.5419 & .72897 & 2.595 & .010 \\
& 2.00 & 462 & 3.4113 & .72725 & & \\
\multirow{2}{*}{ AcP } & 1.00 & 382 & 3.7736 & .60916 & -.980 & .327 \\
& 2.00 & 462 & 3.8155 & .62620 & & \\
EnP & 1.00 & 382 & 3.0720 & .74709 & 1.607 & .108 \\
& 2.00 & 462 & 2.9900 & .72912 & & \\
EfP & 1.00 & 382 & 3.5073 & .68853 & -.396 & .692 \\
& 2.00 & 462 & 3.5253 & .63018 & & \\
\multirow{2}{*}{ Scale } & 1.00 & 382 & 3.6563 & .44563 & 1.678 & .094 \\
& 2.00 & 462 & 3.6050 & .43975 & & \\
\hline
\end{tabular}

Age distribution shows that it is accumulated around the young and rather old parts, about $45 \%$ of the teachers are below the age of 35 (named group number 1), and 55\% of them are above the age of 36, mainly after the age of 40 (named group number 2). Analysis of the independent T sample test of age shows that age doesn't lead to much differences in the sub-scale of AcP, EnP, EfP and the scale itself, it only leads to significant differences in the sub-scales of SP and AtP. Both in SP $\left(\mathrm{M}_{1}=4.3869, \mathrm{M}_{2}=4.2828, \mathrm{t}=1.225, \mathrm{df}=842, \mathrm{p}=.011<0.05\right)$ and in AtP $\left(\mathrm{M}_{1}=3.5419, \mathrm{M}_{2}=3.4113, \mathrm{t}=2.595, \mathrm{df}=842, \mathrm{p}=.010<0.05\right)$, the younger teachers have a higher score than the relatively older teachers, and the differences are significant. This shows that the younger are the teachers, the more positive of their sense of participation and their attitudes towards participation.

\subsubsection{Differences in University Level}

Universities in China fall into 3 types: the key universities (shortened as KU, named number 1), the general universities (shortened as GU, named number 2) and private universities (shortened as PU, named number 3). Teachers from these universities demonstrate many differences in their participation in the reform (shown in table 6).

Table 6. ANOVAs of Teacher Participation in University Level

\begin{tabular}{cccccccccc}
\hline & $\mathrm{KU}(1)$ & \multicolumn{3}{c}{$\mathrm{GU}(2)$} & \multicolumn{3}{c}{$\mathrm{PU}(3)$} & $\mathrm{F}$ & $\begin{array}{l}\text { Post } \\
\text { (Bonferroni) }\end{array}$ \\
\cline { 2 - 6 } & $(\mathrm{n}=265)$ & & $(\mathrm{n}=498)$ & & $(\mathrm{n}=81)$ & & & Hoc \\
& $\mathrm{M}$ & $\mathrm{SD}$ & $\mathrm{M}$ & $\mathrm{SD}$ & $\mathrm{M}$ & $\mathrm{SD}$ & $(2,841)$ & \\
SP & 4.2361 & .62079 & 4.3597 & .56722 & 4.4540 & .63153 & $5.763^{* *}$ & $2>1 ; 3>1$ \\
AtP & 3.2992 & .70583 & 3.5534 & .73150 & 3.5203 & .71582 & $10.930^{* *}$ & $2>1 ; 3>1$ \\
AcP & 3.7646 & .59747 & 3.7789 & .61648 & 4.0093 & .66432 & $5.402^{* *}$ & $3>1 ; 3>2$ \\
EfP & 3.5132 & .68640 & 3.4831 & .64095 & 3.7395 & .61860 & $5.368^{* *}$ & $3>1 ; 3>2$ \\
Scale & 3.5748 & .43600 & 3.6318 & .43675 & 3.7814 & .47053 & $6.886^{* *}$ & $3>1 ; 3>2$ \\
\hline
\end{tabular}

$*$. the significance is $0.05 ;{ }^{* *}$. the significance is 0.005

ANOVAs analysis shows that the differences are very significant in all scales except in EnP. To be specific, teachers of $\mathrm{GU}$ and $\mathrm{PU}$ have a higher sense of participation than those of $\mathrm{KU}\left(\mathrm{MD}_{2-1}=.12360 *\right.$ and $\mathrm{MD}_{3-1}=.21799 *, \mathrm{~F}(2$, $841)=5.763, \mathrm{P}<0.005)$, they are concerned with the reform more. In the aspect of AtP, teachers from GU and PU are more active than those of the $\mathrm{KU}\left(\mathrm{MD}_{2-1}=.24464^{*}\right.$ and $\left.\mathrm{MD}_{3-1}=.22109^{*}, \mathrm{~F}(2,841)=10.930, \mathrm{P}<0.0005\right)$. In the two sub-scales, there do not have significant differences between teachers of GU and PU.

As in the scale, in the sub-scale of AcP and EfP, teachers from the three types of universities show the same tendency: teachers from the PU do better than teachers from KU and GU, while there is no significant differences between 
teachers from KU and GU.

In the sub-scale of EnP, there is no significant difference among the three groups, mainly because the check of environment focuses on the 'soft' aspect as culture, atmosphere, leadership and so on.

\subsubsection{Differences in District Level}

China is a vast country and there are great differences among its geographic zones. According to its traditional classification, universities in the study are put into three kinds: the east developed zone (shortened as EDZ, and named as number 1), the middle developing zone (shortened as MDZ, and named as number 2) and the west under-developing zone (shortened as WDZ, and named as number 3). ANOVAs analysis shows that teachers from different zones participated differently in the reform (shown in table 7).

Table 7. ANOVAs of Teacher participation in District Level

\begin{tabular}{|c|c|c|c|c|c|c|c|c|}
\hline & \multirow{2}{*}{\multicolumn{2}{|c|}{$\begin{array}{l}\operatorname{EDZ}(1) \\
(n=156)\end{array}$}} & \multirow{2}{*}{\multicolumn{2}{|c|}{$\begin{array}{l}\operatorname{MDZ}(2) \\
(n=268)\end{array}$}} & \multirow{2}{*}{\multicolumn{2}{|c|}{$\begin{array}{l}\text { WDZ(3) } \\
(n=412)\end{array}$}} & \multirow{2}{*}{$\mathrm{F}$} & \multirow{3}{*}{$\begin{array}{l}\text { Post Hoc } \\
\text { (Bonferroni) }\end{array}$} \\
\hline & & & & & & & & \\
\hline & M & SD & M & SD & M & SD & $(2,833)$ & \\
\hline SP & 4.4516 & .40244 & 4.3831 & .65393 & 4.2549 & .59150 & $7.918^{* *}$ & $1>3,2>3$ \\
\hline AtP & 3.8984 & .74027 & 3.5080 & .62766 & 3.2829 & .72336 & $44.640^{* *}$ & $1>2,1>3,2>3$ \\
\hline EnP & 3.2705 & .65513 & 2.9687 & .72757 & 2.9811 & .75412 & $10.392^{* *}$ & $1>2,1>3$ \\
\hline EfP & 3.6513 & .58997 & 3.5481 & .63972 & 3.4529 & .67421 & $5.658^{* *}$ & $1>3$ \\
\hline Scale & 3.8072 & .39919 & 3.6525 & .45063 & 3.5484 & .43179 & $20.824^{* *}$ & $1>2,1>3,2>3$ \\
\hline
\end{tabular}

*. the significance is $0.05 ; * *$. the significance is 0.005

Except in the sub-scale of AcP, there are very significant differences among teachers from the three zones in every aspect. In SP, teachers from EDZ and MDZ have a higher sense of participation than those from the WDZ $\left(\mathrm{MD}_{1-3}=.19671^{*}\right.$ and $\left.\mathrm{MD}_{2-3}=.12823 *, \mathrm{~F}(2,833)=7.918, \mathrm{P}<0.005\right)$. And there is no significant difference between teachers from EDZ and MDZ.

In AtP, teachers from EDZ have more active attitudes than those from MDZ and WDZ $\left(\mathrm{MD}_{1-2}=.39036^{*}\right.$ and $\left.\mathrm{MD}_{1-3}=.61541^{*}, \mathrm{MD}_{2-3}=.22506^{*}, \mathrm{~F}(2,833)=44.640, \mathrm{P}<0.005\right)$ and teachers from MDZ have more active attitudes than those of the WDZ.

In EnP, teachers from the EDZ feel much better than those from MDZ and WDZ $\left(\mathrm{MD}_{1-2}=.30186^{*}, \mathrm{MD}_{1-3}=.28944^{*}\right.$, $\mathrm{F}(2,833)=10.392, \mathrm{P}<0.005)$. Teachers from $\mathrm{EDZ}$ have a much better environment for participation than those of the MDZ and WDZ, and there is no significant difference between teachers of MDZ and WDZ.

In EfP, there are significant difference between teachers in EDZ and those from the MDZ, teachers from EDZ feel a better effect of participation than teachers from $\mathrm{MDZ}\left(\mathrm{MD}_{1-3}=.19837^{*}, \mathrm{~F}(2,833)=5.658, \mathrm{P}<0.005\right)$, while there is no significant difference between teachers from EDZ and WDZ, MDZ and WDZ.

In the scale, teacher participation shows a tendency of better participation from East to West. Teachers from EDZ do better than those of MDZ and WDZ, and teachers from $\mathrm{MDZ}$ do better than those from $\mathrm{WDZ}\left(\mathrm{MD}_{1-2}=.15476^{*}\right.$ andMD $\left.{ }_{1-3}=.25881^{*}, \mathrm{MD}_{2-3}=.10405^{*}, \mathrm{~F}(2,833)=20.824, \mathrm{P}<0.005\right)$.

\section{Discussion}

In general, college English teachers do not involve themselves in the reform very deeply and actively. We need to make more efforts to engage them into the reform.

From the analysis, we know that degrees and professional identities do not exert significant differences on teacher participation in the reform, and gender and age have significant changes only in some sub-scales, all these show that these personal factors checked are not the main ones to influence a person to participate in College English reform. What is important here is that in carrying out a reform, the initiators can always depend on the younger teachers as they have more positive attitudes towards reform than the older ones, and also because in a new reform, experience is not as important as vigor, energy and time (Schremer, 1991), which are possessed more by the younger ones. 
However, this also hints that the management should pay more attention to the older teachers, as their actions, positive or negative, will have great impact in the group.

Significant differences of teacher participation show themselves in many aspects of the scale in the district levels. This means that teacher participation will be impacted by the external factors much. As we know that universities of different districts are quite different in believes, resources, cultures, leaderships and so on, they can provide different reform plans and support to the teachers, thus help them to participate in the reform quite differently. The analysis shows that the better the districts are, the better the teachers participated in the reform.

Contrary to the result of the districts, differences of teacher participation in the university level is almost the reverse, which shows that teachers from the key universities are not doing well as those from the general universities and private universities in general, and teachers from the private universities do the best. This is quite puzzling and may be caused by the defect in cluster sampling, which excludes the private universities, and which needs further studying.

Teacher participation in the reform is the key to the success of reform, we should try to find out the effective means to urge and help them into the participation of reform in the future.

\section{Notes}

Note 1. This paper is the achievement of South West Reform Program (2013JY092).

Note 2. Average mean 3.0 and lower stand for teachers' disagreement of the content of statements, 3.0-4.0 shows that they are not sure of the contents, above 4.0 means teachers agree with the statements.

\section{References}

Bee Bee, Sng. (2008). Surface or deep change? How is a curriculum change implemented at ground level? The International Journal of Educational Management, 2(1), 90-106.

Department of Higher Education, Education Bureau. (2007). College English Curricular Requirements. Beijing: Tsinghua University Press.

Dong, Xiaoping. (2008). Teacher Participate in School Curricular Leadership: Meaning, Missed and Construction. Journal of the Chinese Society of Education, 5, 40-44.

Markee Numa. (1997). Managing Curricular Innovation. London: Cambridge University Press.

McKay Sandra Lee. (2010). Researching Second Language Classrooms. London: Routledge Tailor \& Francis Group.

Merschen Jutta, Tra, Wei, Jinping \& Ma, Yongliang. (2014). An Economic Analysis of the University: University Goverflance and the Effects of Faculty Participation in University Decision-Making. Beijing: Intellectual Property Publishing House.

Qin, Xiaoqin. (2009). Questionnaire Research in Foreign Language Teaching. Beijing: Foreign Language Teaching and Research Press.

Richards Jack C. (2002). Curriculum Development in Language Teaching. London: Cambridge University Press.

Schremer Oded E. (1991). The Teacher-A Category in Curriculum Evaluation. Studies in Educational Evaluation. Printed in Great Britain. http://dx.doi.org/10.1016/S0191-491X(05)80107-5

Wang, Jianjun. (2000). Teacher Participate in Curricular Development: Concepts, Effects and Limits. Curricular, Teaching Material and Method, 5, 8-14.

Wang, Shouren \& Wang, Haixiao. (2011). On the State of College English Teaching in China and Its Future Development. Foreign Languages in China, 8(8), 4-17.

Wu, Minglong. (2014). Issues in Questionnaire Statistic Analysis-Using SPSS. Chongqing: Chongqing University Press.

Ying, Hongbiao. (2006). Curricular Implementation and Psychological Changes of Teachers. Global Education, $35(10), 20-25$.

Zhou, Honglin \& Wu, Guoping. (2004). Winning First, Losing Last-Criticism of Profound Basis in China's Traditional Education. In Zhong Qiquan, Wu Guoping ed. Change China's Education. Beijing: Education Science Press. 